\title{
Didactic Adaptation of University Graduates: Efficiency Enhancing Conditions
}

\author{
Olena Savchenko* \\ Bohdan Khmelnytsky National University at Cherkasy, Cherkasy, Ukraine \\ *Corresponding author: svrada@ukr.net
}

Received September 27, 2013; Revised October 10, 2013; Accepted November 22, 2013

\begin{abstract}
The article focuses on the problem of university graduate students adaptation to the professional and pedagogical activity, ways and conditions of the acceleration of this process are also detailed. Factors, which stipulate efficiency of didactic adaptation of new teachers, which include professional and pedagogical orientation of teacher's personality, professional knowledge and abilities, are analyzed. Conditions at which difficulties of educational activity of a new teacher become the mechanisms of effective adaptation process are found. Research of structural elements of young teacher professional adaptation and its basic aspects defined the necessity of purposeful pedagogical management of this process. The purpose of such management consists of providing of quickness, high level and firmness of adaptation, in reduction of moral-psychological costs of young teacher, in the rational use of knowledge, abilities and skills acquired at higher educational establishment, in the economy of spiritual and physical forces, in their creative bloom. The management of adaptation of pedagogical educational establishments graduating student supposes planning, organization, correcting of adaptive process and realization of control after it's following.
\end{abstract}

Keywords: university graduates, new teacher, didactic adaptation, difficulty of professional and pedagogical activity, factors for optimization

Cite This Article: Olena Savchenko, "Didactic Adaptation of University Graduates: Efficiency Enhancing Conditions." American Journal of Educational Research 1, no. 11 (2013): 538-542. doi: 10.12691/education-111-14.

\section{Introduction}

Resolving optimization problems of socio-economic development requires significant improvement in training practitioners in many areas of work. This approach will require rapid adaptation of people to constantly changing conditions of their profession.

The growth of social role of school and teacher urgently requires further enrichment and development of the theory and practice of pedagogical education, because the formation of teacher's personality - enough difficult object of social management, conditioned by combination of a number of social-pedagogical, psychological and physiological factors.

In Ukraine much is done for the increase of level of pedagogical education: maintenance is perfected, the quality of teaching and education of future teachers rises, the material and technical base of educational establishments develops, professional growth of teaching staff proceeds.

Pedagogical educational establishments will be able to solve their task and social expectations will be justified only when they manage to train such teachers whose general and professional culture will develop by passing ahead rates in relation to a rising generation and bulk of workers and that each of them in a full degree could execute tasks laid on him by the society: to capture the richness of the theory and practice of education, to form the own style and methods of work on this basis.

However the dialectics of modern pedagogical education generates a contradictory situation, when not all teachers in a sufficient degree are prepared to the high rank and corresponded to the social status. Pedagogical educational establishments are reproached that: many their graduating students poorly own a method and technique of teaching, they are helpless in the decision of especially educated tasks, are not able to establish durable connections with families of studying, etc.; practical becoming of teachers takes place very slowly, delaying on years at times; some part of young specialists is not prepared to educational work at school.

Distinctly understanding, that the graduating student of pedagogical higher educational establishment cannot be examined as the fully formed specialist, however pedagogical higher educational establishment must integrate the difficult process of the professional becoming of future teacher (professional pedagogical orientation, professional selection, the dynamics of the professional becoming of future teacher in the conditions of higher educational establishment training, post-graduate activity and adaptation of young teacher).

There are the costs on all stages of teacher's professional training, the shortages, that in final analysis negatively affect the quality of training. At first, the effective mechanism of professional orientation at school is absent and considerable quantity of young people in 
pedagogical higher educational establishment turns out not defining their calling, life purpose, higher educational establishment training remains the formal finding of speciality. Secondly, the basic support in education is done on scientific disciplines at insufficient attention to the practical and pedagogical courses.

Teaching pedagogics - which is the main science of a teacher - leaves much to be desired. Until now very often in the courses of pedagogics out-of-date approaches on principles and forms of organization of educational process at school are expounded, the discord in conceptions of methods of teaching and education is not overcame, new approaches to the cardinal questions of theory and practice are not studied, students are badly acquainted with modern fundamental researches in pedagogical science. As a result, the graduating students of pedagogical educational establishments turn out poorly trained to work at school, to the successful decision of new intricate problems of teaching and education, are lost at meeting with the first difficulties, lost the interest to their business, badly seize the professional trade.

The important place in the system of continuing professional development is taken by the postgraduate work, adaptation to the requirements of professional and educational activities, since these activities ensure the formation of a practitioner. Professional skills of new teachers indicate positive adaptation that ensures efficiency in teaching and professional development. Adaptability as a consequence of the adaptation influences the quality of education at educational institutions and the further stability of teaching.

The problem of professional adaptation of new teachers should be studied on the basis of comprehensive analysis of the achievements in pedagogy, in-depth monitoring of the quality of education and teaching at schools, and the efficiency assessment of graduates' teaching at schools.

\section{Adaptation as a Pedagogical Problem}

The problem of young teacher adaptation is difficult and multifactor process, being the special object of innerschool and out-of-school management, efficiency of which depends on plenitude of knowledge about its essence and mechanisms. The management by adaptation processes is possible only thanks to achievements of pedagogics, social psychology and sociology.

Post educational establishment activity of young teacher plays deciding role in the professional becoming, and the analysis of the system of actions and conduct comes forward the enough grounded criterion of estimation of professional training level of graduating student of pedagogical educational establishments. One of indexes of level of young teacher training to implementation of the role of teacher-educator is the adaptation at school staff, motive force of which is the contradiction between the professional training, preliminary pictures of teaching work, social expectations and real requirements, concrete terms of activity, everyday school practice

The system of the teaching staff training is the integral complex of structural elements, being in certain connections and relations, interactive with each other and forming integral unity. This connection is the reserved chain: school - pedagogical educational establishments school. From the quality of general training of schools graduates' - entrants of pedagogical educational establishments - depends the quality of future teacher training. In the same queue, general training of young people depends on qualification of school teachers: knowledge and pedagogical trade acquired in pedagogical educational establishment.

More precisely, this connection consists of the following elements: school - university entrant freshman - student of senior courses - student of final course - young teacher. Weakness of any of associate and single links unavoidable results in violation of all slender system of highly skilled teacher training. It is obvious that each of stages has the features, the tasks ad all of them are important. However the fact that the pedagogical activity have started has the fundamental value for a young teacher, and the analysis of the system of his/her actions and conduct comes forward the enough grounded criterion of estimation of level of professional training. The adaptation at school staff is major description of activity of graduating student of pedagogical educational establishment which is put in the grade of actual scientific problems foremost thanks to the practical meaningfulness.

The problem of adaptation has become the subject of many studies in psychology and pedagogy, where multiple tasks and ways of adaptation to the conditions of student life and learning in higher education institutions of different profiles have been considered (T. Alekseeva, Y. Bohonkova, L. Grigorenko, S. Gura, V. Laherev, G. Levkivska, S. Selivestrov and others); adaptations to the profession has been analyzed in the works by N. Golubeva, S. Izbash, T. Katkova, D. Lopareva, I. Obles, V. Pavlushenko, L. Petlevanna and others.

Currently, the problem of adaptation of new teachers to professional and educational activities has been explored in several directions.

The first direction includes works in which the authors have formulated the concept of "professional commitment", outlined the criteria, indicators, levels of readiness (A. Voytenko, M. Kobzev, V. Kolupaev, V. Nikitenko).

The second direction is referred to studies examining the social and psychological adaptation of new teachers. These studies analyze the problem of adaptation of university graduates to the new social environment, the norms of collective and professional educational activity (L. Borisova, S. Ovdiy, S. Skuby, M. Sturova, N. Chaikina and others).

\section{Fenomenon of University Graduates' Didactic Adaptation}

The study of professional and educational adaptation of graduates in the unity of the psychological, social, educational, and didactic aspects makes the third direction, where the first step is to emphasize the fundamental research results achieved by $\mathrm{O}$. Moroz. The scholar developed a methodological approach to correct interpreting of the adaptation of new teachers in their independent professional and educational activities.

The research into the nature of "adaptation" in psychology, sociology, and pedagogy led to the assertion 
that this phenomenon is related not only to the processes of human adaptation to the new conditions, but also to individual personal and professional development. This conclusion is based on the concept of personalization (A. Petrovsky) and proper time regulation (phase - E. Klimov, stages - T. Zeyer, T. Kudryavtseva, T. Levitan).

The analysis of numerous studies on the problem of adaptation in education (T. Aleksieeva, I. Boiko, L. Voloshin, S. Hur, O. Moroz, V. Tsybulko and others) enabled us to prove that "learning adaptation" and "professional adaptation" are similarly defined in pedagogy. However, the category of individual professional adaptation taught in universities is not clearly defined.

Therefore, analyzing interpretations of such basic concepts as "professional adaptation", "socio-professional adaptation", "readiness for professional adaptation", "adaptation readiness of prospective teachers to the profession " we came to the conclusion that the phenomenon of adaptation to the profession is a process of gradual immersion of an individual in the future profession. It is multifunctional; it is an essential condition for and a means of identifying a person with professional activities, optimizing the interaction with the professional environment that are necessary components of professional development. At the same time it has been proved that the importance of the phenomenon is in the cyclic nature of changes that take place in the student's psyche and controls the student adaptation to the conditions of professional activity [1].

Some aspects of difficulties in adaptation of new teachers are analyzed in studies of N. Kuzmina, G. Mannapova where theoretical problems were considered: the definition of the concept "difficulties" was proposed, the nature of this phenomenon was described, difficulties in the classification of teacher's professional activities were given. Difficulties in forming some structural components of educational activities during the training in universities are analyzed by A. Akimova, V. Yelmanova, G. Zasobinova, L. Sokolova whose works are a logical continuation of the research made by N. Kuzmina. Teaching difficulties in teaching activities of new teachers were explored by T. Polyakova; she developed a method of learning difficulties by finding their causes and ways to improve university teaching and recertification teacher training, which will help to overcome the difficulties in teaching activities. Learning difficulties in new teachers' professional activities is the fourth direction in research related to professional adaptation of new teachers.

Analysis of the problem of professional adaptation of new teachers enables to conclude that the problem of adaptation of young teachers has not been sufficiently research. Such concepts as structure, functions, and mechanisms of adaptation of new teachers require further research. There is also a need to study ways and means of managing adaptation. We should give detailed reflection to the structural elements of professional adaptation including adaptation to training activities - didactic adaptation. Due to the fact that different disciplines differ in teaching methods, professional adaptation should include the peculiarities of a particular academic subject.

\section{Adaptation of New Teachers to Teaching a Foreign Language}

Analyzing the level of professional and teaching activities of new foreign language teachers from the perspective of adaptation to teaching a foreign language, we found that only $9.6 \%$ of new teachers with one year of teaching experience, $9.8 \%$ of teachers with two years of experience, and $11.3 \%$ of new teachers after teaching for three years reached a high adaptability. However, almost $35 \%$ of all young foreign language teachers demonstrate low didactic adaptation.

To understand the most significant challenges in the new foreign language teachers' professional adaptation the research method has been developed. The data obtained are sufficient and reliable that objectively reflect the weaknesses in the professional activities.

With the help of expert assessment and self-assessment method we found that graduates of the Department of Foreign Languages experience serious difficulties in learning activities that are crucial for developing pedagogical skills of a modern teacher: the ability to develop academic work skills makes $83.1 \%$; the ability to develop interest in reading and needs for knowledge makes $74.5 \%$; the understanding of the content of new curricula and textbooks scores $71.2 \%$; the ability to diversify foreign languages learning techniques makes $69.6 \%$.

The average ratio of these skills varies from 3.08 to 3.42, and self-assessment varies from 3.09 to 3.48 . Particular attention is paid to the difficulties that new teachers encounter in planning and conducting lessons. It was found that the new teachers had certain difficulties in predicting challenges that their students might experience in learning activities. The new teachers couldn't selfreflect their lessons, had classroom discipline management problems. However, these difficulties become less intense after two or three years of independent professional development.

The lack of methodological training of new foreign language teachers leads to difficulties in setting the main lesson objectives (84.1\%), selecting teaching material related to the topic of the lesson (83.6\%), and identifying the amount of teaching material (82.8\%).

The new foreign language teachers experience difficulties with organizing extra-curricular activities (74.2 \%), individual work with students (72.9\%), conducting tutoring (68.6\%). As a result, only $11.3 \%$ of high school students participate in foreign language extracurricular activities. Although extra-curricular activities are of great importance to motivate student learning and increase interest in the discipline, $82.5 \%$ of new teachers admit that they received insufficient university training in this type of activity.

Monitoring new foreign language teachers' activities enables us to identify one drawback in teacher training that affects teaching effectiveness in schools. Most teachers said that they had a good command of a foreign language as a means of communication, but had a difficulty with using a foreign language as a means of instruction. This means that university formal training does not provide prospective language teachers with a professional language.

The level of capture by a young teacher by teaching activity unlike the level of the professional trade is determined by not only the measure of creation in operation by knowledge but also measure of independence 
in formulation and decision of didactic tasks, by the character of errors and shortages in their realization. Success of educational activity of young teacher in the first years of independent work largely depends also on the orientation of personality of graduating student, features of co-operation with the leader of the last pedagogical practice and teacher, in some measure of the folded structure of activity.

But deciding factor determining success in didactic adaptation of young teacher, there is ability to overcome nascent difficulties in educational work. The graduating students of pedagogical educational establishments, as supervisions show, have mainly the weak picture of degree of training to teaching activity and even underestimate to all complication of educational process. Therefore, meeting the first difficulties in work, they sometimes lose a confidence in the forces, are disappointed in a select profession. What is necessary to be understood under difficulties in work of young teacher, is their nature and ways of removal which?

\section{Teaching Difficulties of New Teachers}

Analyzing the difficulties new teachers experience when they cope with their professional tasks, we need to emphasize that the reason is the quality of formal training in the discipline. It does lack psychological, pedagogical, and methodological training of future specialists.

The results of this study allow us to qualify teaching difficulties that new foreign language teachers experience as difficulties of an adaptation period, the existence of which substantially reduces the effectiveness of professional development, quality of teaching, thus impeding didactic adaptation. However, realization of the difficulties and the need to overcome them provides mechanisms of didactic adaptation [2].

Level of new teachers' readiness for teaching and educating activities out of which we distinguish teacher's personal professional and pedagogical efficiency, professional and instructional management skills substantially affect the effectiveness of new teachers' didactic adaptation. So, professional development and didactic adaptation of a new teacher are affected by a number of factors: individual personal development of a young teacher (career choice motives, internal psychological attitude to teaching activities, professional competence, inspirational motives), as well as social and psychological factors connected with the teaching environment (the qualifications of the teaching staff; administration, colleagues' and students' attitude to a new teacher, student-teacher relationship, psychological climate in the team, and creativity of team work, etc.). Depending on the intensity and duration of exposure, all the factors have different effects on teaching effectiveness.

\section{Factors for Optimization of Didactic Adaptation}

An important factor for optimization of didactic adaptation is to improve the process of training future teachers by strengthening professional and educational focus on the full range of educational activities, the formation of the students' professionally significant qualities required by practice. In the pedagogical university professionalization means its pedagogisation.

The continuation of the work started in higher education setting is an activity aimed at intensifying the process of didactic adaptation of new teachers during their independent work in school. The study gives us reasons to believe that didactic adaptation depends on the degree and nature of the assistance that the new teacher receives from teaching staff, school administration, and experienced coworkers. Correlation analysis of didactic adaptation with received assistance interprets this assistance as an important way to help optimize the adaptation process. Teacher-mentor should render a gradual diagnostic, prescriptive, controlling and stimulating assistance aimed at reducing the intensity of the difficulty of teaching activities, strengthening the achieved level of adaptability and outline further areas of cooperation to optimize didactic adaptation [3].

The pedagogical aspect of problem of management of young teachers professional adaptation includes the scientific search of such maintenance, such forms and methods of work with graduating students by which pedagogical school staff, pedagogical educational establishments would be able reliably to remove, warn and soften the negative consequences of unadaptation, to accelerate the process of young teachers professional adaptation to new requirements of pedagogical profession and terms of school life.

The effectiveness of the mentoring depends on new teachers' self-reflection and self-education. Professional self-education of a new teacher is an independent, conscious, systematic acquisition of professional knowledge and skills in addition to the skills received in formal training to eliminate the weaknesses and to improve teaching practices.

Being a flexible form of post-school training, selfeducation allows taking into consideration the teacher's individual needs. Building on improved professional skills new teachers can eliminate weaknesses in instructional strategies. The effectiveness of new teachers' selfeducation depends on compliance with some rules of selfeducation: conscious mastery of scientific and theoretical knowledge, learning advanced pedagogical experience, regular studies, consistency, and communication with teaching staff.

This study makes it possible to formulate the concept of didactic adaptation of a university graduate entering a teaching profession. This concept is understood as the complex process of self-vocational and educational activities aimed at practical mastering of the teaching profession, which serves as a prerequisite for mastering teaching skills based on skills, learned and constantly updated, active process of overcoming teaching difficulties, interaction with teaching staff of the institution, efficient self-organized self-education for effective professional performance.

\section{Conclusion}

The study demonstrated that the process of didactic adaptation of new teachers can be substantially manageable, become shorter in terms, and more effective 
if we outline the ways and conditions of its optimization taking into account the contradiction between the needs of society and the real level of training graduates to teaching activities. Mentoring ew teachers in this case will be based on knowledge of adaptation mechanisms and factors that determine the adaptive capacity of the new teacher.

To conclude, we note that the didactic adaptation of university graduate is a holistic process aimed at improving new teacher's teaching practices, a comprehensive system to improve training of future teachers and management of their didactic adaptation during independent work in school. The effectiveness of didactic adaptation of new teachers is influenced by consistent support of teacher-mentors who understand the main features of adaptation of new teachers, their levels of adaptability and self-educational activities. This allows of adjusting and guiding the process of didactic adaptation to achieve the goals and objectives raised.

One indicator of the low level of general formal training of new teachers, manifested in the adaptation period is the high intensity of the teaching difficulties that, when realized by the new teachers, can serve as mechanisms that influence the effectiveness of the adaptation process.

Summarizing the foregoing, there is foundation to assert that the research tasks are fulfilled and the goal is reached. Theoretical and experimental materials confirm a hypothesis that the process of young teacher professional adaptation became largely guided, thanks to: a) to providing of diagnostics of readiness of graduating students of pedagogical educational establishments to pedagogical activity; b) to the theoretical ground of essence, role and value of young teacher professional adaptation; c) to creation at experimental school of terms for acceleration of adaptation; d) to the concrete suggestions directed on the improvement of professional training of future teachers in pedagogical educational establishments and the accepted practical measures of purposeful help to the young teachers; e) to development and introduction of the having a special purpose programs of co-operation of pedagogical educational establishments and school on work with young teachers; f) wellorganized aggregate of organizational-pedagogical measures from the side of organs of folk education on the increase of adaptation possibilities of beginners of teachers; g) realization of the system of pedagogical management by professional adaptation of graduating student of pedagogical educational establishments.

\section{References}

[1] Prima, R. M, Students' adaptation to the professional and pedagogical activity as a scientific problem. [Online]. Available: http://www.nbuv.gov.ua.

[2] Levkivska, G. P, An adaptation of freshmen in the conditions of higher educational establishment, Publishing house of Scientific and methodological center of higher education, K., 2001, 128.

[3] An educational process at higher pedagogical establishment, an editor Moroz, O. G, NPU named after M. Dragomanov, Kyiv, 2001, 338.

[4] Sannikova, O. P, Kyznetsova, O. P, Adaptiveness of personality, Cherkasov, N. P, Publisher, Odessa, 2009, 258.

[5] Moroz, O. H, Professional adaptation of young teacher, Kyiv state pedagogical university named after O. M, Gorkogo, Kyiv, 1980, 95.

[6] Moroz, A. H, Professional adaptation of graduating student of pedagogical higher educational establishment, PhD thesis, Kyev, 1984, 403.

[7] Moroz, O. H, Professional adaptation of young teacher, Vyshcha shkola, Kyiv, 1980, 94.

[8] Chaykina, N. O, Psychological structure of professional adaptation of young teacher, Thesis for a candidate's degree, Kyiv, 1997, 18.

[9] Halus, O. M, Professional adaptation of students in the conditions of level pedagogical higher educational establishment, KhPA, Khmelnytsky, 2007, 473.

[10] Kurlyand, Z. N, The becoming of positive Ya-koncepcii of future teacher, PNTs APN Ukrayiny, Cherkasov, N. P. Publisher, Odesa, 2005, 163. 